\title{
Commentary: Detection is only part of the equation-Does elevated risk alone warrant screening?
}

\author{
Richard Liu, MD, and Biniam Kidane, MD, MSc
}

\author{
From the Section of Thoracic Surgery, University of Manitoba, Winnipeg, Manitoba, Canada. \\ Disclosures: Authors have nothing to disclose with regard to commercial support. \\ Received for publication July 5, 2019; accepted for publication July 5, 2019; available ahead of print Aug 9, 2019. \\ Address for reprints: Biniam Kidane, MD, MSc, Section of Thoracic Surgery, University of Manitoba, 820 Sher- \\ brook St, Room GE-611, Winnipeg, Manitoba R3A 1R9, Canada (E-mail: bkidane@hsc.mb.ca). \\ J Thorac Cardiovasc Surg 2019;158:1255-6 \\ $0022-5223 / \$ 36.00$ \\ Copyright $(2019$ by The American Association for Thoracic Surgery \\ https://doi.org/10.1016/j.jtcvs.2019.07.002
}

In their article in this issue of the Journal, "Cumulative Nonsmoking Risk Factors Increase the Probability of Developing Lung Cancer,' Bravo-Iñiguez and colleagues ${ }^{1}$ use models from 2 established studies (the Liverpool Lung Project ${ }^{2}$ and Prostate, Lung, Colorectal, and Ovarian Cancer Screening Trial ${ }^{3}$ ) to illustrate the cumulative effect of nonsmoking risk factors on risk of development of lung cancer. Bravo-Iñiguez and colleagues ${ }^{1}$ demonstrate that a combination of nonsmoking risk factors can significantly increase lung cancer even in patients with a limited smoking history. They call for the use of risk calculation tools to expand lung cancer screening programs to include highrisk patients with smoking histories not captured within the National Lung Screening Trial (NLST) ${ }^{4}$ criteria.

Current guidelines already recommend including patients outside the NLST inclusion criteria. ${ }^{5,6}$ It is well established that risk factors other than age and smoking history are important in the development of lung cancer, and this is reflected in these recommendations. In addition, the Nederlands-Leuven Longkanker Screenings Onderzoek (NELSON) trial demonstrated a similar benefit of screening despite a more inclusive population than the NLST. ${ }^{7}$

It is important, however, to understand that ad hoc screening is not the same as a systematic screening program. $^{8}$ An effective screening program requires a method for systematic invitation, participation of more than $70 \%$ of the target population, and the necessary infrastructure and resources to diagnose and treat patients identified in the program. ${ }^{9}$ Increasing detection rates, as suggested by this study, would seem prima facie to be beneficial; however, the expansion of the lung cancer screening population may increase demand for diagnostic and therapeutic interventions to a point that is not sustainable in many health systems. This may have an unintended effect of supporting ad hoc screening, among other unanticipated consequences.

There are a few other important considerations for readers when interpreting the findings and conclusions of the article by Bravo-Iñiguez and colleagues. ${ }^{1}$ First, this

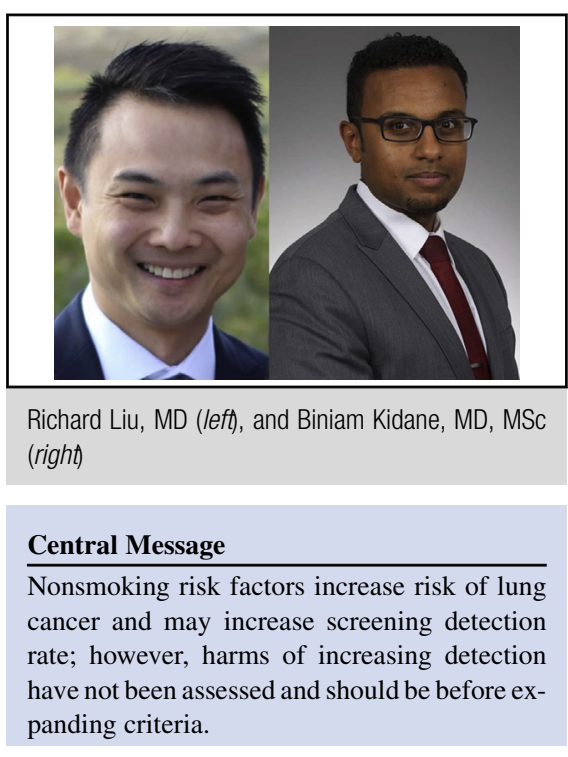

See Article page 1248.

study derived models from preexisting data sets and is not the product of new data. The derived risk models, as well as the conclusions inferred therefrom, are thus subject to the same limitations as the original data sources. The Liverpool Lung Project ${ }^{2}$ and the Prostate, Lung, Colorectal, and Ovarian Cancer Screening Trial ${ }^{3}$ had limitations, such as generalizability, that are beyond the scope of this editorial but are worth considering. This limitation is exacerbated by using an aggregated model, such as the one described by Bravo-Iñiguez and colleagues. ${ }^{1}$ Second, there are many that argue that lung cancer screening may, in fact, be more harmful than helpful, even when using NLST or NELSON criteria. ${ }^{10}$ Many of their arguments center on the harms that have been documented with investigation and treatment of screening-detected nodules that might have never caused a problem for the patient. Further fuel to this fire is the intrigue surrounding the evolution and execution of the NELSON trial, including the ongoing absence of published trial results long after its presentation on the international stage in 2018. Even if the reader does not espouse these viewpoints, they should provide some context for interpreting the findings of this study. It is certainly logical to suggest that expanding screening criteria to patients at a higher calculated risk of development of lung cancer will increase the detection rate of lung cancers; however, this study has not addressed whether 
it is in fact helpful or harmful to patients or society at large to increase the detection rate in such a way.

This study illustrates that the use of age and smoking history alone are inadequate criteria to discriminate all patients who might benefit from computed tomographic screening for lung cancer. Intuitively, the use of risk prediction tools to expand the target population makes sense. For expanded screening to be effective, however, it must be implemented in a fashion that ensures high levels of systematic participation in the target population and adequate resources to manage the fallout. In addition, the harms associated with increasing detection need to be assessed before expanding screening criteria.

\section{References}

1. Bravo-Iñiguez CE, Fox SW, De Leon LE, Tarascio JN, Jaklitsch MT, Jacobson FL. Cumulative nonsmoking risk factors increase the probability of developing lung cancer. J Thorac Cardiovasc Surg. 2019;158:1248-54.e1.

2. Cassidy A, Myles JP, van Tongeren M, Page RD, Liloglou T, Duffy SW, et al. The LLP risk model: an individual risk prediction model for lung cancer. Br J Cancer. 2008;98:270-6.
3. Tammemagi CM, Pinsky PF, Caporaso NE, Kvale PA, Hocking WG, Church TR, et al. Lung cancer risk prediction: prostate, lung, colorectal and ovarian cancer screening trial models and validation. J Nat Cancer Inst. 2011;103:1058-68.

4. National Lung Screening Trial Research T, Aberle DR, Adams AM, Berg CD, Black WC, Clapp JD, et al. Reduced lung-cancer mortality with low-dose computed tomographic screening. N Engl J Med. 2011;365:395-409.

5. Jaklitsch MT, Jacobson FL, Austin JH, Field JK, Jett JR, Keshavjee S, et al. The American Association for Thoracic Surgery guidelines for lung cancer screening using low-dose computed tomography scans for lung cancer survivors and other high-risk groups. J Thorac Cardiovasc Surg. 2012;144:33-8.

6. Wood DE, Kazerooni EA, Baum SL, Eapen GA, Ettinger DS, Hou L, et al. Lung cancer screening, version 3.2018, NCCN clinical practice guidelines in oncology. J Natl Compr Canc Netw. 2018;16:412-41.

7. De Koning H, Van Der Aalst C, Ten Haaf K, Oudkerk M. PL02.05: effects of volume CT lung cancer screening: mortality results of the NELSON randomised-controlled population based trial. J Thorac Oncol. 2018; 13(Suppl):S185.

8. Wilson JM, Jungner G. Principles and Practices of Screening for Disease. Geneva, Switzerland: World Health Organization; 1968. Available at: http:// whqlibdoc.who.int/php/WHO_PHP_34.pdf. Accessed June 23, 2019.

9. Bach PB, Mirkin JN, Oliver TK, Azzoli CG, Berry DA, Brawley OW, et al. Benefits and harms of CT screening for lung cancer: a systematic review. JAMA. 2012;307:2418-29. Errata in: JAMA. 2012;308:1324, JAMA. 2013;309:2212.

10. Prasad V, Lenzer J, Newman DH. Why cancer screening has never been shown to "save lives" — and what we can do about it. BMJ. 2016;352:h6080. 